\title{
THE EFFECTS OF EDUCATION ON THE MAJOR LIFE ACTIVITIES OF ROAD TRAFFIC INJURY VICTIMS CONCERNING HEALTH SATISFACTION STATUS
}

\author{
Waqas $^{1 *}$, Intikhab Alam ${ }^{2}$, Mussawar Shah ${ }^{3}$, Khalid Nawab ${ }^{4}$ \\ ${ }^{1 * 2,2,3}$ Department of Rural Sociology, The University of Agriculture, Peshawar, Pakistan; ${ }^{4}$ Department of Agric. \\ Extension Education \& Communication, The University of Agriculture, Peshawar, Pakistan. \\ Email: ${ }^{1 *}$ waqass@aup.edu.pk, ${ }^{2}$ intikhab@aup.edu.pk, ${ }^{3}$ dr.mussawarshah@aup.edu.pk, ${ }^{4}$ nawab_aup@aup.edu.pk
} Article History: Received on $13^{\text {th }}$ March 2021, Revised on $1^{\text {st }}$ April 2021, Published on $6^{\text {th }}$ April 2021

\begin{abstract}
Purpose of the study: To examine the satisfaction of the health status of RTI victims and to measure the association between the satisfaction of health status with the prevailing level of participation of RTI victims in various major life activities.
\end{abstract}

Methodology: This study follows a cross-sectional research design. A comprehensive interview schedule was designed and pre-tested before the actual process of data collection. For data analysis, SPSS v.20 was run for obtaining univariate, bivariate, and multivariate analysis.

Main Findings: At a bivariate level, it was found that RTI victims were having difficulty in walking, standing, sitting, and dysfunctional memory status had significantly associated with low health satisfaction. Furthermore, at the multivariate level, the victims with low educational status were more likely to report limitations in Major Life Activities (MLA), ultimately affecting their health satisfaction status.

Applications of this study: This research's findings can apply to such studies that emphasize the sociological perspectives for minimizing traffic crashes. Moreover, it also provides the role of education in controlling traffic injuries in the south Asian region.

Novelty/Originality of this study: This study is the first-ever attempt to determine the effects of MLA limitations on the health satisfaction status. Apart from describing the phenomenon from a sociological perspective, the article also enlightens the role of education in minimizing RTI injuries.

Keywords: Major Life Activities Limitation, Health Satisfaction Status, Road Traffic Injuries, Education.

\section{INTRODUCTION}

Road traffic crashes killed approximately 1.35 million people on roads, and 30 to 50 million become seriously injured (Konlan et al., 2020; Global Status Report on Road Safety, 2018). It is a global health concern worldwide projected to be the $7^{\text {th }}$ leading cause of death till 2030 (World Health Organization, 2015). Furthermore, the WHO declared in 2015 that traffic injuries were the $6^{\text {th }}$ highest disease burden which is ahead of AIDS and diabetes (World Health Organization, 2019). RTIs have painful physical (Ghadipasha et al., 2015; Dhondt et al., 2013), psychological (Mayou \& Bryant, $\underline{2003}$ ), and social consequences (Másilková, 2017) that required adequate medical, psychological, and social treatments for the patient's full and effective health recovery.

Health is a state of complete physical, mental and social well-being, not merely the absence of a disease or infirmity (Evans et al., 2013). Health status in connection to life satisfaction could be traced in the context of subjective wellbeing. According to Diener (1984), subjective well-being is comprised of both affective well-being and life satisfaction. Similarly, according to Okun and Stock (1987) and Reyes Fernández et al. (2015), health status and life satisfaction are critical dimensions for studying subjective well-being, which has dramatically increased over the past few decades (Diener, 2013). However, research regarding health satisfaction status relating to people victimized in traffic crashes remains very limited; indeed, almost non-existent in Pakistan. A substantial amount of literature shows that traffic injury victims were more likely to report low or fair health status. The overall quality of life significantly reduces after RTI (Rissanen et al., 2017), and the long-term impact of injury affect the individual's life satisfaction (Jacobsson \& Lexell, 2013). Furthermore, social variables like medical barriers negatively influenced the health status while better household finances, living environment, and social support positively associated (Lin \& Cheng, 2019).

As Kesavayuth et al. (2015) stated, illness negatively affects individuals' health satisfaction because of various activity limitations. Similarly, RTIs also adversely affected the MLA (walking or moving outside their home unaided) of traffic victims (Alemany et al., 2013). MLA are those essential and basic functions to most people's daily lives like walking, performing manual tasks, talking, hearing, seeing, sleeping, and working (What Are Major Life Activities?, 2021; Rights, United States Commission on Civi, 2017). The MLA problems were significantly associated with health status dissatisfaction (Stalnacke, 2011; De Jong et al., 2011).

Besides, health satisfaction is linked to the higher socioeconomic status of people. Higher education or higher occupational status and those who dispose of more significant financial resources tend to enjoy better health at all ages (Sanderson \& Scherbov, 2014; Eikemo et al., 2008). Furthermore, higher education levels were found predictors of 
better functioning after the crash, while low education was associated with a lower functioning level (Walton et al., 2013; Kim, 2011).

The current literature focused more on the impact of traffic injuries on health regarding direct consequences (Polinder et al., 2015; Mashreky et al., 2010). Similarly, data concerning RTI in the police department and hospitals reflect the direct and short-term health consequences but cannot provide the long-term scenario (Berg et al., 2016; Haghparast-Bidgoli et al., 2013).

Less research focused on long-term health-related quality of life (Rissanen et al., 2020; Gopinath et al., 2017); which remains very limited, almost non-existent in the context of MLA limitations and educational status. The proposed study assessed the effects of education on the major life activities of RTI victims concerning health satisfaction status. This study portrayed various suggestions or recommendations based on study findings that will help policymakers formulate policies for the effective mainstreaming of the victims into mainstream society and their positive contribution to achieving developmental goals.

\section{Objectives of the study}

1. To examine the satisfaction of the health status of RTI victims.

2. To measure the association of MLA with HSS of the RTI victims.

\section{METHODOLOGY}

\section{Study design}

In this study "Cross-Sectional" research design was used. This design is best suited to studies aimed at finding out the prevalence of a phenomenon, situation, problem, attitude or issue, by taking a cross-section of the population. This design displays an overall picture existing at the time of the study. Such studies are called cross-sectional concerning both times of exploration and study population ( $\underline{\text { Kumar, 2019). }}$.

\section{Study Universe}

The current study's universe was District Malakand of Khyber Pakhtunkhwa. Khyber Pakhtunkhwa is one of the four provinces of Pakistan. It is the $3^{\text {rd }}$ largest province of the country by the size of both population and economy, though the smallest one in area. Khyber Pakhtunkhwa is divided into seven divisions and 35 districts. District Malakand is one of them, which is administratively divided into 02 Tehsil (Sama Ranizai \& Swat Ranizai). Tehsil Sama Ranizai is a hilly area with an intensive road network. Due to its geographical location, this tehsil is a transit route for millions of passengers and tourists. Therefore, the roads traffic in this tehsil is bustling, particularly during summer and winter vacations, when there is a high tourist influx. Due to physical geography, high road mobility, and narrow meandering roads, the rate of Road Traffic Collision (RTC) and its associated fatalities and injuries are spiking in the area. The current study's focus was limited to RTC survivors of 12 randomly selected UC (Table 1) in tehsil Sama Ranizai of District Malakand.

\section{Sample size and Sampling}

Stratified Multistage Random Sampling was used to select a representative sample from the targeted population. Data were collected from twelve rural units (Dargai, Karkhai, Wartir, Sakhakot, Palay, Koper, Herosha, Dheri, Malakand, Gari Usmani Khel, Batkhela, and Thana Bandajat). A total of 807 fatal accidents were registered in the study area during 2018. The record for the year 2018 was obtained from the Emergency Department of District Headquarter Hospital Batkhela and Tehsil Headquarter Hospital Dargai which was completed in all respect. The Emergency Department (ED) had recently allocated a separate register for Road Traffic Accident (RTA). The record for the year 2019 was not as much completed as required for the study.

Similarly, the record for the year 2017 and before was aligned in combined registers for all types of emergencies (RTA, history of fall, burn etc.). Almost there were 25 registers stored in the record by the ED. So, finding RTAs cases in those gigantic registers was a daunting task and also time-consuming. Therefore, data for the year 2018 was selected for this study. Below is the formula for calculating sample size for the known population, as Chaudhry suggested (2009).

$n=\frac{\mathrm{N} \hat{\mathrm{p}} \widehat{\mathrm{q}} \mathrm{Z}^{2}}{\widehat{\mathrm{p}} \mathrm{q}^{2}+\mathrm{Ne}^{2}-\mathrm{e}^{2}} \quad$ (Chaudhry, 2009)

Where

$N$ represents Total Road Traffic Crashes $=807$,

$p$ for Population Portion, which is equal to 0.50,

$q=0.50$,

$Z$ represents Confidence Level which is equal to 1.96,

$e$ illustrates the Margin of Error which is equal to 0.043, 
Based on the above formula, the required sample size for a population of 807 traffic crash survivors was 274 . These survivors bear the brunt of traffic injury in the shape of disability or functional impairment or some functional limitations. The proportion allocation of the required sample size was performed to each union council. Subsequently, the respondents were randomly selected through a simple random sampling technique. Table 1 shows the details of the proportionally allocated sample size:

The formula used for proportion allocation as under:

Each stratum sample size required:

$n_{h}=\left(\mathrm{N}_{\mathrm{h}} / \mathrm{N}\right) * \mathrm{n}$

$\mathrm{n}_{\mathrm{h}}$ represents the required sample size for stratum $h$,

$N_{h}$ illustrates the population size for stratum $h$,

$N$ illustrates the total population size, and

$n$ is the total sample size

Table 1: Allocation of required sample to selected Union Councils

\begin{tabular}{lll}
\hline UC Name & $\begin{array}{l}\text { Population size / Total number } \\
\text { of Crash Survivors }\end{array}$ & Sample Size \\
\hline Batkhela & 139 & 47 \\
\hline Dargai & 120 & 41 \\
\hline Thana & 56 & 19 \\
\hline Dheri & 36 & 12 \\
\hline Malakand & 69 & 23 \\
\hline Wartir & 65 & 22 \\
\hline Kharkay & 81 & 28 \\
\hline Sakhakot & 62 & 21 \\
\hline Palay & 73 & 25 \\
\hline Koper & 35 & 12 \\
\hline Herosha & 34 & 12 \\
\hline Gari Usmani & 37 & 13 \\
\hline TOTAL & 807 & 274 \\
\hline
\end{tabular}

Source: Office record of DHQ Hospital Batkhela \& THQ Hospital Dargai, 2018

\section{Characteristics of respondents}

Road Traffic Injuries (RTI) is defined as "An event that occurs on a way or street open to public traffic; resulting in one or more persons being injured or killed, where at least one moving vehicle is involved." (Sinha, 2017). All those RTI victims were included in this study who were observed with the following characteristics:

i. A person who has been injured in a traffic collision and that collision has occurred between at least one mechanical means of transportation, i.e., a collision between vehicles, vehicles, persons, animals, or buildings.

ii. Victims of RTI residing in the District Malakand region

iii. Victims of RTI that received moderate to untreatable injuries and were shifted to hospital

iv. RTI victim who felt the brunt of traffic injuries for several days, months, or years.

Study's Variables

Table 2: Study's Variables

\begin{tabular}{lcl}
\hline Background Variables & Independent Variables & Dependent Variable \\
\hline Educational Status & Major Life Activities Limitations & Health Satisfaction Status \\
\hline
\end{tabular}

\section{Data Collection Tools}

An interview schedule was designed for collecting primary data and translated into the national language (Urdu). It was pre-tested with a small group of 20 victims of RTI (Kothari, 2004), and inconsistencies and ambiguities were removed subsequently rectified before the actual data collection process. The researcher personally collected data from the male respondents. However, due to cultural constraints, it was not possible to approach female respondents for data collection. Therefore, a female investigator was hired and trained for collecting data from female respondents. 


\section{Operationalization of Variables}

Major life activities limitations mean the extent to which an RTI victims' MLA (walking, performing manual tasks, talking, hearing, seeing, sleeping, and working) have reduced after traffic injury. Health satisfaction status means how satisfied the RTI victims were with their health after the traffic injury. Injury means how much the body organs are damaged in a traffic collision. These injuries range from minor to life-threatening. It includes cuts, scrapes, scratches, bruises, and punctured skin. Symptoms like slowness, weakness, and lack of muscle coordination related to speech function commonly come from dysarthria. The initial onset of dysarthria reduces speech intelligibility; it also limits the speaker's communicative ability. Furthermore, restrict social participation because dysarthria is a consistent indicator (Guo \& Togher, 2008).

\section{Measurement of Variables}

Seven items review-based scale was developed to measure the major life activities limitation, where all items were negatively framed. Hence, positive responses on 4 or more items on the scale were considered RTI victims' limitations in major life activities. Short Assessment of Patient Satisfaction (SAPS) scale was used to measure the health satisfaction status of RTI victims (Hawthorne et al., 2014). The 7 items SAPS scale was contextualized according to the need of the study. All items were positively framed; therefore, positive responses on 4 or more items were considered high health satisfaction status while less than 4 were considered low health satisfaction.

\section{Reliability analysis}

For assuring internal consistency of the instrument scale, reliability analysis was performed through Cronbach's Alpha test. A scale with an Alpha is equal or greater than $\alpha=>0.6$ was considered internally consistent and suitable for indexation practiced by other researchers (Mohamad et al., 2015). In this study, the reliability of Cronbach's Alpha value for the major life activity limitation scale was 0.63 , and the health satisfaction status scale was 0.90 .

\section{Data Analysis}

The collected data finalized in all respect were entered into SPSS v.20 and coded for its analysis. The data then analyzed using bivariate and multivariate statistical techniques.

\section{Bivariate Analysis}

At bivariate analysis, the independent variable's association with the dependent variable was performed by indexing the study variable separately. Subsequently, the independent variable was cross-tabulated with the dependent variable i.e., health satisfaction status.

$$
\begin{gathered}
\chi^{2}=\sum \frac{\left(O_{i}-E_{i}\right)^{2}}{E_{i}} \\
x^{2}=\text { chi-square } \\
O_{i}=\text { observed values } \\
E_{i}=\text { expected value }
\end{gathered}
$$

\section{Multivariate Analysis}

The independent variable having Cronbach's $\alpha=0.63$ was indexed, subsequently cross-tabulated with dependent variables to determine variations between the two variables. The multivariate analyses were performed by associating independent variables with the dependent variable while controlling educational status as background variable, resulting in spurious and non-spuriousness of relationship. The standard for spurious relationships was set in this study based on significance levels of the association between the variables. If at least one category of the controlled variable was found nonsignificant, then the relationship between independent and dependent variables was recorded as spurious. Similarly, if all categories carried significant value, then Tau-b values were taken into consideration. If all Tau-b values recorded variations, then the relationship was recorded as spurious, otherwise non-spurious.

\section{RESULTS/FINDINGS}

\section{Bivariate Analysis}

Table 3 shows the association between the independent and dependent variables. It was found that $75.2 \%$ of RTI victims had Difficulty in Standing/Walking (DISW), who was observed in low HSS compared to 39\% who had no such dysfunctional status; however, they reported low HSS. It is further evident from the chi-square and Kendall Tau-b values where the association of DISW was found highly significant $(\mathrm{P}=0.000)$ and moderate negative $\left(\mathrm{T}^{\mathrm{b}}=-0.358\right)$ with $\mathrm{HSS}$. Similarly, $74.7 \%$ had difficulty in sitting who had low HSS compared to $43.3 \%$ who reported no difficulty in sitting. The association between difficulty in sitting with HSS was found highly significant $(\mathrm{P}=0.000)$ and negative $(\mathrm{Tb}=-0.319)$, suggesting that difficulty in sitting amongst the RTI victims plays a central role in influencing the HSS. The same status were inquired from respondents which illustrates that $85 \%$ had Memory Limitation (ML) who were found in low HSS 
compared to 55\% who did not have ML. The association between ML and HSS was found highly significant $(P=0.000)$ and negative $\left(T^{b}=-.246\right)$ with HSS.

The result further reveals that $69 \%$ of respondents were found in low HSS who had dysarthria disorder after traffic injury compared to $60 \%$ who had no such problem. The association of dysarthria disorder with HSS was found non-significant $(p=0.233)$ and negative $\left(T^{b}=-0.057\right)$, which means that dysarthria disorder did not influence the HSS. Similarly, the respondents who had Auditory Functional Limitations (AFL) were found 71\% low HSS compared to 59.7\% who had no AFL. The results further explore that association between AFL was non-significant $(p=0.1540)$ and negative $\left(T^{b}=-\right.$ $0.073)$ with HSS. The respondents (61.9\%) who had Visual Limitations (VL) were found in low HSS compared to those respondents $(60.9 \%)$ who had no VL. The association between VL was non-significant $(P=0.561)$ and negative $\left(T^{b}=-\right.$ .006) with HSS, which shows that VL did not influence the HSS of RTI victims. The study's findings further explore that $68.3 \%$ of respondents had Disturbed Sleeping (DS) who were found in low HSS compared to $58.9 \%$ who had no DS. However, the association between DS was found non-significant $(P=0.119)$ and weak negative $($ Tau-b $=-.080)$ with HSS, which means that DS has a negative association with HSS of RTI victims.

Table 3: Association between MLA limitation and health satisfaction status

\begin{tabular}{|c|c|c|c|c|c|c|}
\hline \multirow{2}{*}{ Statement } & \multicolumn{4}{|c|}{ HSS of RTI victim } & \multirow[b]{2}{*}{$\begin{array}{l}\text { Chi-square } \\
\text { value }\end{array}$} & \multirow{2}{*}{$\begin{array}{l}\text { Kendall } \\
\text { Tau-b value }\end{array}$} \\
\hline & Attitude & $\overline{\text { High HSS }}$ & Low HSS & Total & & \\
\hline \multirow{2}{*}{$\begin{array}{l}\text { You feel difficulty in standing or } \\
\text { walking for a short period of time }\end{array}$} & Yes & $41(24.8)$ & $124(75.2)$ & $165(100)$ & \multirow{2}{*}{$\begin{array}{l}x^{2}=35.152 \\
p=0.000\end{array}$} & \multirow{2}{*}{ Tau-b $=-0.358$} \\
\hline & No & $66(60.6)$ & $43(39.4)$ & $109(100)$ & & \\
\hline \multirow[t]{2}{*}{ You have problem in sitting } & Yes & $39(25.3)$ & $115(74.7)$ & $154(100)$ & \multirow{2}{*}{$\begin{array}{l}x^{2}=27.836 \\
p=0.000\end{array}$} & \multirow{2}{*}{ Tau-b $=-0.319$} \\
\hline & No & $68(56.7)$ & $52(43.3)$ & $120(100)$ & & \\
\hline \multirow{2}{*}{$\begin{array}{l}\text { You cannot learn things easily - } \\
\text { mean your memory has been } \\
\text { affected }\end{array}$} & Yes & $8(14.8)$ & $46(85.2)$ & $54(100)$ & \multirow{2}{*}{$\begin{array}{l}x^{2}=16.598 \\
p=0.000\end{array}$} & \multirow[b]{2}{*}{ Tau-b $=-0.246$} \\
\hline & No & $99(45)$ & $121(55)$ & $220(100)$ & & \\
\hline \multirow{2}{*}{$\begin{array}{l}\text { You cannot talk to someone easily } \\
\text { and communicate your message to } \\
\text { other person }\end{array}$} & Yes & $9(31)$ & $20(69)$ & $29(100)$ & \multirow{2}{*}{$\begin{array}{l}x^{2}=0.876 \\
p=0.233\end{array}$} & \multirow[b]{2}{*}{ Tau-b $=-0.057$} \\
\hline & No & $98(40)$ & $147(60)$ & $245(100)$ & & \\
\hline \multirow{2}{*}{$\begin{array}{l}\text { You cannot listen the other person, } \\
\text { mean your auditory sense has been } \\
\text { affected }\end{array}$} & Yes & $9(29)$ & $22(71)$ & $31(100)$ & \multirow{2}{*}{$\begin{array}{l}x^{2}=1.474 \\
p=0.1540\end{array}$} & \multirow[b]{2}{*}{ Tau-b $=-0.073$} \\
\hline & No & $98(40.3)$ & $145(59.7)$ & $243(100)$ & & \\
\hline \multirow{2}{*}{$\begin{array}{l}\text { You feel difficulty in watching } \\
\text { things }\end{array}$} & Yes & $8(38.1)$ & $13(61.9)$ & $21(100)$ & \multirow{2}{*}{$\begin{array}{l}x^{2}=0.009 \\
p=0.561\end{array}$} & \multirow{2}{*}{ Tau-b $=-0.006$} \\
\hline & No & $99(39.1)$ & $154(60.9)$ & $253(100)$ & & \\
\hline \multirow[t]{2}{*}{ Your sleep is disturbed after injury } & Yes & $19(31.7)$ & $41(68.3)$ & $60(100)$ & \multirow[t]{2}{*}{$x^{2}=1.760$} & \multirow[b]{2}{*}{ Tau-b $=-0.080$} \\
\hline & No & $88(41.1)$ & $126(58.9)$ & $214(100)$ & & \\
\hline
\end{tabular}

\section{MULTIVARIATE ANALYSIS}

Table 4 illustrates the association of MLA limitation and HSS controlling education as a background variable. The results explained that the influence of MLA limitation on the HSS of illiterate respondents was non-significant $(\mathrm{p}=0.482)$; however, weak negative $\left(\mathrm{T}^{\mathrm{b}}=-0.105\right)$. In contrast, such influence in the context of secondary education was found highly significant $(\mathrm{p}=0.000)$ and moderate negative $\left(\mathrm{T}^{\mathrm{b}}=-0.287\right)$. Furthermore, the influence of the MLA in the context of higher education was non-significant $(\mathrm{p}=0.892)$. Simultaneously, a weak negative value of $\mathrm{T}^{\mathrm{b}}=-.018$ illustrates a less negative association between the independent and dependent variables. Based on the variation in chisquare values and Kendall's $\mathrm{T}^{\mathrm{b}}$ values, the association between MLA limitation and HSS in the context of education was spurious. Hence, education explained variation in the association of independent and dependent variables.

\section{DISCUSSION/ANALYSIS}

The most frequent and common injuries in traffic crashes are head injuries that caused memory loss or learning abilities (Mayou et al., 2000; Másilková, 2017). Hence, major life activities' limitations are directly associated with low health satisfaction (De Jong et al., 2011). Most traffic injuries cause dysarthria (Kim et al., 2009), affecting speech function, slowness, weakness, and lack of muscle coordination. 
Table 4: Association between MLA limitation and health satisfaction status controlling education

\begin{tabular}{|c|c|}
\hline Education & $\begin{array}{l}\text { STATISTICS } \\
\left(\text { Chi-square- } \mathrm{x}^{2}-\mathrm{P} \text {-value \& Kendall's-T }{ }^{\mathrm{b}}\right)\end{array}$ \\
\hline Illiterate & $\begin{array}{l}\mathrm{x}^{2}=0.495 \\
\mathrm{p}=0.482 \\
\mathrm{~T}^{\mathrm{b}}=-0.105\end{array}$ \\
\hline $\begin{array}{l}\text { Secondary Education } \\
\text { (Matric/Intermediate) }\end{array}$ & $\begin{array}{c}\mathrm{x}^{2}=12.940 \\
\mathrm{p}=0.000 \\
\mathrm{~T}^{\mathrm{b}}=-.217\end{array}$ \\
\hline $\begin{array}{l}\text { Higher Education } \\
\text { (Graduation above) }\end{array}$ & $\begin{array}{l}\mathrm{x}^{2}=0.018 \\
\mathrm{p}=0.892 \\
\mathrm{~T}^{\mathrm{b}}=-0.018\end{array}$ \\
\hline
\end{tabular}

Dysarthria reduces speech intelligibility; also, it limits the communicative ability. These limiting functions further affect social participation (Guo \& Togher, 2008). Our result found that dysarthria disorder did not influence the HSS. More precisely, the dysarthria problem could be less severe amongst the respondents of this study; otherwise, Hoffman et al. $\underline{(2005)}$ study revealed much more dissatisfaction from health because of dysarthria. The result further demonstrates that AFL and VL did not influence the HSS of RTI victims; however, Łabudzki \& Tasiemski (2013) found more positive outcomes on blind and visually impaired individuals as the physical activity increases their subjective quality. Sleeping is one of the essential parts of MLA, which was excessively reported by most of the RTI victims (Philip et al., 2014). This study found that disturbed sleeping has a negative association with the HSS of RTI victims. It has been concluded from the above results that the majority of RTI victims were found chronic limitation in their MLA. Furthermore, the association between MLA and HSS was assessed while controlling education as a background variable. It was found that RTI victims with low education were more likely to report limitations in major life activities and health satisfaction status.

\section{CONCLUSION}

It has been concluded that the majority of RTI victims were found in chronic limitation performing their MLA. Furthermore, the association between MLA and HSS was assessed while controlling education as a background variable. It concluded that RTI victims with low education were more likely to report limitations in major life activities; subsequently, they were observed in low health satisfaction status.

\section{LIMITATION AND STUDY FORWARD}

This study was confined to the RTI victims who were confronted with traffic crashes and survived in it. Further research studies need to be carried out on the families left behind and their socioeconomic status, particularly women's psychological well-being.

\section{ACKNOWLEDGEMENT}

This study did not receive any financial support from any agency, organization or institution. The researchers pay gratitude towards the victims who participated in the study by sparing their times

\section{AUTHORS CONTRIBUTION}

- The principal author (Waqas) has designed the central theme of the research work and carried all important steps and procedures.

- Dr. Intikhab Alam made the overall supervision of this research study.

- Dr. Mussawar Shah provided the technical and updated literature support time to time.

- Prof. Dr. Khalid Nawab was mentoring the whole research process.

\section{REFERENCES}

1. Alemany, R., Ayuso, M., \& Guillén, M. (2013). Impact of road traffic injuries on disability rates and long-term care costs in Spain. Accident Analysis \& Prevention, 60, 95-102. https://doi.org/10.1016/j.aap.2013.08.016

2. Berg, H.-Y., Ifver, J., \& Hasselberg, M. (2016). Public health consequences of road traffic injuries - Estimation of seriously injured persons based on risk for permanent medical impairment. Transportation Research Part F: Traffic Psychology and Behaviour, 38, 1-6. https://doi.org/10.1016/j.trf.2015.12.007

3. Chaudhry, S. M. (2009). An Introduction to Statistical Theory (8th ed. 2009 ed.). Ilmi Kitab Khana, Lahore, Pakistan. 
4. De Jong, J. R., Vlaeyen, J. W. S., de Gelder, J. M., \& Patijn, J. (2011). Pain-Related Fear, Perceived Harmfulness of Activities, and Functional Limitations in Complex Regional Pain Syndrome Type I. The Journal of Pain, 12(12), 1209-1218. https://doi.org/10.1016/j.jpain.2011.06.010

5. Dhondt, S., Macharis, C., Terryn, N., Van Malderen, F., \& Putman, K. (2013). Health burden of road traffic accidents, an analysis of clinical data on disability and mortality exposure rates in Flanders and Brussels. Accident Analysis \& Prevention, 50, 659-666. https://doi.org/10.1016/j.aap.2012.06.019

6. Diener, E. (1984). Subjective well-being. Psychological Bulletin, 95(3), 542-575. https://doi.org/10.1037/00332909.95.3.542

7. Diener, E. (2013). The Remarkable Changes in the Science of Subjective Well-Being. Perspectives on Psychological Science, 8(6), 663-666. https://doi.org/10.1177/1745691613507583

8. Eikemo, T. A., Huisman, M., Bambra, C., \& Kunst, A. E. (2008). Health inequalities according to educational level in different welfare regimes: a comparison of 23 European countries. Sociology of Health \& Illness, 30(4), 565-582. https://doi.org/10.1111/j.1467-9566.2007.01073.x

9. Evans, D. B., Hsu, J., \& Boerma, T. (2013). Universal health coverage and universal access. Bulletin of the World Health Organization, 91(8), 546-546A. https://doi.org/10.2471/blt.13.125450

10. Ghadipasha, M., Vaghefi, S. S., Kazemi Esfeh, S., Teimoori, M., Ouhadi, A. R., \& Mirhosseini, S. M. (2015). An annual analysis of clinical diagnosis versus autopsy findings in fatal motor vehicle accident in legal medicine organization of Kerman province, Iran. Journal of Forensic and Legal Medicine, 34, 164-167. https://doi.org/10.1016/j.jflm.2015.05.013

11. Gopinath, B., Jagnoor, J., Elbers, N., \& Cameron, I. D. (2017). Overview of findings from a 2-year study of claimants who had sustained a mild or moderate injury in a road traffic crash: prospective study. BMC Research Notes, 10(1), 1-7. https://doi.org/10.1186/s13104-017-2401-7

12. Guo, Y. E., \& Togher, L. (2008). The impact of dysarthria on everyday communication after traumatic brain injury: A pilot study. Brain Injury, 22(1), 83-98. https://doi.org/10.1080/02699050701824150

13. Haghparast-Bidgoli, H., Saadat, S., Bogg, L., Yarmohammadian, M. H., \& Hasselberg, M. (2013). Factors affecting hospital length of stay and hospital charges associated with road traffic-related injuries in Iran. BMC health services research, 13(1), 1-11. https://doi.org/10.1186/1472-6963-13-281

14. Hawthorne, G., Sansoni, J., Hayes, L., Marosszeky, N., \& Sansoni, E. (2014). Measuring patient satisfaction with health care treatment using the Short Assessment of Patient Satisfaction measure delivered superior and robust satisfaction estimates. Journal of Clinical Epidemiology, 67(5), 527-537. https://doi.org/10.1016/j.jclinepi.2013.12.010.

15. Herero, V. G., \& Extremera, N. (2010). Daily life activities as mediators of the relationship between personality variables and subjective well-being among older adults. Personality and Individual Differences, 49(2), 124129. https://doi.org/10.1016/j.paid.2010.03.019

16. Hoffman, J. M., Yorkston, K. M., Shumway-Cook, A., Ciol, M. A., Dudgeon, B. J., \& Chan, L. (2005). Effect of Communication Disability on Satisfaction With Health Care. American Journal of Speech-Language Pathology, 14(3), 221-228. https://doi.org/10.1044/1058-0360(2005/022)

17. Jacobsson, L., \& Lexell, J. (2013). Life satisfaction 6-15 years after a traumatic brain injury. Journal of Rehabilitation Medicine, 45(10), 1010-1015. https://doi.org/10.2340/16501977-1204

18. Kesavayuth, D., Rosenman, R. E., \& Zikos, V. (2015). Personality and health satisfaction. Journal of Behavioral and Experimental Economics, 54, 64-73. https://doi.org/10.1016/j.socec.2014.11.005

19. Kim, E. G., Lee, D. G., Jeong, W. J., Cho, H. S., Bae, J. I., Kim, S. H., \& Kim, K. H. (2009). The Clinical Study on 500 Cases with Traffic Accident Patients Admitted in Oriental Medical Hospital. Journal of Acupuncture Research, 26(5), 29-38

20. Kim, Y.-J. (2011). A systematic review of factors contributing to outcomes in patients with traumatic brain injury. Journal of Clinical Nursing, 20(11-12), 1518-1532. https://doi.org/10.1111/j.1365-2702.2010.03618.x

21. Konlan, K. D., Doat, A. R., Mohammed, I., Amoah, R. M., Saah, J. A., Konlan, K. D., \& Abdulai, J. A. (2020). Prevalence and Pattern of Road Traffic Accidents among Commercial Motorcyclists in the Central Tongu District, Ghana. The Scientific World Journal, 2020, 1-10. https://doi.org/10.1155/2020/9493718

22. Kothari, C. R. (2004). Research Methodology $2^{\text {nd }}$ Ed. New Age International (P) Ltd., Publishers.

23. Kumar, R. (2019). Research Methodology: A Step-by-Step Guide for Beginners (5th ed.). SAGE Publications Ltd.

24. Łabudzki, J., \& Tasiemski, T. (2013). Physical Activity and Life Satisfaction in Blind and Visually Impaired Individuals. Human Movement, 14(3), 210-216. https://doi.org/10.2478/humo-2013-0025

25. Lin, C.-Y., \& Cheng, T.-C. (2019). Health status and life satisfaction among people with disabilities: Evidence from Taiwan. Disability and Health Journal, 12(2), 249-256. https://doi.org/10.1016/j.dhjo.2018.10.008

26. Mashreky, S. R., Rahman, A., Khan, T. F., Faruque, M., Svanström, L., \& Rahman, F. (2010). Hospital burden of road traffic injury: Major concern in primary and secondary level hospitals in Bangladesh. Public Health, 124(4), 185-189. https://doi.org/10.1016/j.puhe.2010.01.004

27. Másilková, M. (2017). Health and social consequences of road traffic accidents. Kontakt, 19(1), e43-e47. https://doi.org/10.1016/j.kontakt.2017.01.007 
28. Mayou, R. A., Black, J., \& Bryant, B. (2000). Unconsciousness, amnesia and psychiatric symptoms following road traffic accident injury. British Journal of Psychiatry, 177(6), 540-545. https://doi.org/10.1192/bjp.177.6.540

29. Mayou, R. A., Ehlers, A., \& Bryant, B. (2002). Posttraumatic stress disorder after motor vehicle accidents: 3 year follow-up of a prospective longitudinal study. Behaviour Research and Therapy, 40(6), 665-675. https://doi.org/10.1016/s0005-7967(01)00069-9

30. Mayou, R., \& Bryant, B. (2003). Consequences of road traffic accidents for different types of road user. Injury, 34(3), 197-202. https://doi.org/10.1016/S0020-1383(02)00285-1

31. Mohamad, M. M., Sulaiman, N. L., Sern, L. C., \& Salleh, K. M. (2015). Measuring the Validity and Reliability of Research Instruments. Procedia - Social and Behavioral Sciences, 204, 164-171. https://doi.org/10.1016/j.sbspro.2015.08.129

32. Okun, M. A., \& Stock, W. A. (1987). Correlates and Components of Subjective Well-Being Among the Elderly. Journal of Applied Gerontology, 6(1), 95-112. https://doi.org/10.1177/073346488700600108

33. Peden, M., Scurfield, R., Sleet, D., Mohan, D., Hyder, A. A., Jarawan, E., \& Mathers, C. (2004). World Report on Road Traffic Injury Prevention. World Health Organization.

34. Philip, P., Chaufton, C., Orriols, L., Lagarde, E., Amoros, E., Laumon, B., Akerstedt, T., Taillard, J., \& Sagaspe, P. (2014). Complaints of Poor Sleep and Risk of Traffic Accidents: A Population-Based Case-Control Study. PLoS ONE, 9(12), e114102. https://doi.org/10.1371/journal.pone.0114102

35. Polinder, S., Haagsma, J., Bos, N., Panneman, M., Wolt, K. K., Brugmans, M., Weijermars, W., \& van Beeck, E. (2015). Burden of road traffic injuries: Disability-adjusted life years in relation to hospitalization and the maximum abbreviated injury scale. Accident Analysis \& Prevention, 80, $193-200$. https://doi.org/10.1016/j.aap.2015.04.013

36. Reyes Fernández, B., Rosero-Bixby, L., \& Koivumaa-Honkanen, H. (2015). Effects of Self-Rated Health and Self-Rated Economic Situation on Depressed Mood Via Life Satisfaction Among Older Adults in Costa Rica. Journal of Aging and Health, 28(2), 225-243. https://doi.org/10.1177/0898264315589577

37. Rights, United States Commission on Civi. (2017). Helping Employers Comply With the Ada: An Assessment of How the United States Equal Employment Opportunity Commission Is Enforcing Title I of the Americans With Disabilities Act (Classic Reprint). Forgotten Books.

38. Rissanen, R., Berg, H.-Y., \& Hasselberg, M. (2017). Quality of life following road traffic injury: A systematic literature review. Accident Analysis \& Prevention, 108, 308-320. https://doi.org/10.1016/j.aap.2017.09.013

39. Rissanen, R., Ifver, J., Hasselberg, M., \& Berg, H.-Y. (2020). Quality of life following road traffic injury: the impact of age and gender. Quality of Life Research, 29(6), 1587-1596. https://doi.org/10.1007/s11136-02002427-3

40. Sanderson, W. C., \& Scherbov, S. (2014). Measuring the Speed of Aging across Population Subgroups. PLoS ONE, 9(5), e96289. https://doi.org/10.1371/journal.pone.0096289

41. Sinha, A. P. (2017). Study of Orthopedic Injuries Pattern by Road Traffic Accident Victims. International Journal of Life-Sciences Scientific Research, 3(2), 961-963. https://doi.org/10.21276/ijlssr.2017.3.2.14

42. Stalnacke, B.-M. (2011). Life satisfaction in patients with chronic pain - relation to pain intensity, disability, and psychological factors. Neuropsychiatric Disease and Treatment, 683. https://doi.org/10.2147/ndt.s25321

43. Walton, D. M., MacDermid, J. C., Giorgianni, A. A., Mascarenhas, J. C., West, S. C., \& Zammit, C. A. (2013). Risk Factors for Persistent Problems Following Acute Whiplash Injury: Update of a Systematic Review and Meta-analysis. Journal of Orthopaedic \& Sports Physical Therapy, 43(2), 31-43. https://doi.org/10.2519/jospt.2013.4507

44. What are major life activities? (2021, February 1). ADA National Network. https://adata.org/faq/what-aremajor-life-activities\#:\% 7E:text=Major\%20life\%20activities\%20are\%20those,performing\%20manual\%20ta sks\%2C\%20and\%20working.

45. World Health Organization. (2015). WHO | Injuries and violence: the facts 2014. WHO | Injuries and Violence: The Facts 2014. https://www.who.int/violence_injury_prevention/media/news/2015/Injury_violence facts 2014/en/\#:\%7E:text=A\%20new\%20document \%20by\%20WHO,and\%20poisonings\%2C\%20among\%20other $\% 20$ causes

46. World Health Organization. (2018, June). Global status report on road safety 2018. https://www.who.int/vi olence injury prevention/road safety status/2018/en/.

47. World Health Organization. (2019, March 26). Disease burden and mortality estimates. https://www.w o.int/healthinfo/global_burden_disease/estimates/en/ 